\title{
New method to study oxidative damage and antioxidants in the human small bowel: effects of iron application
}

Citation for published version (APA):

Troost, F. J. J., Saris, W. H. M., Haenen, G. R. M. M., Bast, A., \& Brummer, R. J. M. (2003). New method to study oxidative damage and antioxidants in the human small bowel: effects of iron application. American Journal of Physiology-Gastrointestinal and Liver Physiology, 285(2), G354-G359. https://doi.org/10.1152/ajpgi.00422.2002

Document status and date:

Published: 01/01/2003

DOI:

10.1152/ajpgi.00422.2002

Document Version:

Publisher's PDF, also known as Version of record

\section{Please check the document version of this publication:}

- A submitted manuscript is the version of the article upon submission and before peer-review. There can be important differences between the submitted version and the official published version of record.

People interested in the research are advised to contact the author for the final version of the publication, or visit the DOI to the publisher's website.

- The final author version and the galley proof are versions of the publication after peer review.

- The final published version features the final layout of the paper including the volume, issue and page numbers.

Link to publication

\footnotetext{
General rights rights.

- You may freely distribute the URL identifying the publication in the public portal. please follow below link for the End User Agreement:

www.umlib.nl/taverne-license

Take down policy

If you believe that this document breaches copyright please contact us at:

repository@maastrichtuniversity.nl

providing details and we will investigate your claim.
}

Copyright and moral rights for the publications made accessible in the public portal are retained by the authors and/or other copyright owners and it is a condition of accessing publications that users recognise and abide by the legal requirements associated with these

- Users may download and print one copy of any publication from the public portal for the purpose of private study or research.

- You may not further distribute the material or use it for any profit-making activity or commercial gain

If the publication is distributed under the terms of Article $25 \mathrm{fa}$ of the Dutch Copyright Act, indicated by the "Taverne" license above, 


\section{New method to study oxidative damage and antioxidants in the human small bowel: effects of iron application

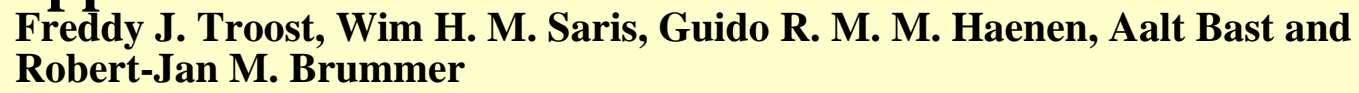

Freddy J. Troost, Wim H. M. Saris, Guido R. M. M. Haenen, Aalt Bast and

Robert-Jan M. Brummer \\ AJP - GI 285:354-359, 2003. First published Apr 30, 2003; doi:10.1152/ajpgi.00422.2002}

You might find this additional information useful...

This article cites 26 articles, 5 of which you can access free at: http://ajpgi.physiology.org/cgi/content/full/285/2/G354\#BIBL

Updated information and services including high-resolution figures, can be found at: http://ajpgi.physiology.org/cgi/content/full/285/2/G354

Additional material and information about AJP - Gastrointestinal and Liver Physiology can be found at: http://www.the-aps.org/publications/ajpgi

This information is current as of February 23, 2005.

AJP - Gastrointestinal and Liver Physiology publishes original articles pertaining to all aspects of research involving normal or abnormal function of the gastrointestinal tract, hepatobiliary system, and pancreas. It is published 12 times a year (monthly) by the American Physiological Society, 9650 Rockville Pike, Bethesda MD 20814-3991. Copyright @ 2005 by the American Physiological Society. ISSN: 0193-1857, ESSN: 1522-1547. Visit our website at http://www.the-aps.org/. 


\title{
New method to study oxidative damage and antioxidants in the human small bowel: effects of iron application
}

\author{
Freddy J. Troost, ${ }^{1}$ Wim H. M. Saris, ${ }^{1}$ Guido R. M. M. Haenen, ${ }^{2}$ \\ Aalt Bast, ${ }^{2}$ and Robert-Jan M. Brummer ${ }^{3}$ \\ Departments of ${ }^{1}$ Human Biology and ${ }^{2}$ Pharmacology, Maastricht University and \\ ${ }^{3}$ Department of Gastroenterology, University Hospital Maastricht, All Nutrition and \\ Toxicology Research Institute Maastricht, 6229 ER Maastricht, The Netherlands
}

Submitted 26 September 2002; accepted in final form 24 April 2003

Troost, Freddy J., Wim H. M. Saris, Guido R. M. M. Haenen, Aalt Bast, and Robert-Jan M. Brummer. New method to study oxidative damage and antioxidants in the human small bowel: effects of iron application. Am J Physiol Gastrointest Liver Physiol 285: G354-G359, 2003. First published April 30, 2003; 10.1152/ajpgi.00422.2002.-Iron may induce oxidative damage to the intestinal mucosa by its catalyzing role in the formation of highly reactive hydroxyl radicals. This study aimed to determine iron-induced oxidative damage provoked by a single clinical dosage of ferrous sulfate and to elucidate the antioxidant defense mechanisms in the human small intestine in vivo. A double-lumen perfusion tube was positioned orogastrically into a $40-\mathrm{cm}$ segment of the proximal small intestine in six healthy volunteers $(25 \pm 5 \mathrm{yr})$. The segment was perfused with saline and subsequently with saline containing $80 \mathrm{mg}$ iron as ferrous sulfate at a rate of $10 \mathrm{ml} / \mathrm{min}$. Intestinal fluid samples were collected at 15-min intervals. Thiobarbituric acid reactive substances concentrations as an indicator of lipid peroxidation increased significantly from $0.07 \mu \mathrm{M}$ (range, $0-0.33 \mu \mathrm{M}$ ) during saline perfusion to $3.35 \mu \mathrm{M}$ (range, 1.19-7.27 $\mu \mathrm{M}$ ) during iron perfusion $(P<0.05)$. Nonprotein antioxidant capacity increased significantly from $474 \mu \mathrm{M}$ (range, 162$748 \mu \mathrm{M}$ ) to $1,314 \mu \mathrm{M}$ (range, 674-1,542 $\mu \mathrm{M})(P<0.05)$. These data show that a single dosage of ferrous sulfate induces oxidative damage and the subsequent release of an antioxidant in the small intestine in vivo in healthy volunteers.

duodenum; epithelium; lipid peroxidation; small intestine; oxidative stress

THE PREVALENCE OF IRON DEFICIENCY anemia in Europe and North America is $1 \%$ in adult males and $14 \%$ in adult females (5). The usual treatment of iron deficiency anemia involves oral iron supplementation with ferrous salts. Ferrous salts, prescribed in amounts $\leq 195 \mathrm{mg}$ of elemental iron/day divided over three single dosages as ferrous sulfate, -fumarate or -gluconate, respectively (7), are commonly preferred over ferric salts because of their higher bioavailability. Oral ferrous iron therapy may, however, induce oxidative stress due to its catalyzing role in Fenton chemistry, resulting in the production of highly reactive hydroxyl

Address for reprint requests and other correspondence: F. J. Troost, Dept. of Human Biology, Nutrition and Toxicology Research Institute Maastricht, Maastricht University, PO Box 616, 6200 MD Maastricht, The Netherlands (E-mail f.troost@hb.unimaas.nl). radicals $(6,23)$. They can react with any molecule in their direct environment, resulting in a cascade of reactions in which lipids, proteins, and DNA may get damaged. Production of reactive oxygen species (ROS), such as superoxide anion radicals, hydroxyl radicals, and hydrogen peroxide, is normally balanced by the antioxidant system. Excessive ROS production, however, induces a disturbance in the pro- and antioxidant balance, resulting in oxidative damage.

Oral iron therapy, commonly indicated in people with an elevated risk for developing iron deficiency, such as children, adolescents, the elderly, (pregnant) women, vegetarians, and athletes, may induce considerable gastrointestinal (GI) side effects, such as nausea, vomiting, heartburn, abdominal pain, and constipation, in contrast to intravenous iron treatment (2). Iron-induced oxidative damage in the intestine after oral ingestion of iron supplements may, in part, be responsible for these GI side effects. Additionally, oral iron therapy in patients suffering from GI disorders associated with an impaired mucosal or systemic antioxidant capacity, such as inflammatory bowel disease or celiac disease, may attribute to the development of major oxidative damage $(8,13,16,19,27)$.

Oral iron supplements were shown to aggravate lactic acid-induced damage to the barrier function of the small intestine epithelium (9) and to promote colon tumorigenesis in mice (22) and inflammatory processes in rats with colitis $(1,20)$. Moreover, electron paramagnetic resonance spectroscopy in rats in vivo showed that oral iron therapy with ferrous sulfate resulted in iron-mediated oxidative stress through hydroxyl radicals in the small intestine. This stress resulted in a decrease in cell turnover, shortening of microvillus height, and partial or complete erosion of the microvilli in the duodenum (24). Epidemiological studies showed a role of dietary iron in the development of colon cancer (26). Additionally, ROS may induce development of several forms of cancer $(4,18)$.

Because of the complexity of the direct measurement of oxidative damage in the lumen of the human small intestine in vivo, no data are available regarding the

The costs of publication of this article were defrayed in part by the payment of page charges. The article must therefore be hereby marked "advertisement" in accordance with 18 U.S.C. Section 1734 solely to indicate this fact. 
effects of clinically prescribed amounts of iron on oxidative damage in the human intestine in vivo. Also, little is known about the antioxidant defense mechanisms against ROS production in the intestine. For this purpose, we developed a perfusion technique to directly quantify oxidative damage and antioxidant capacity in vivo in the small intestine in healthy adults. This study aimed to determine iron-induced oxidative damage provoked by a single clinical dosage of ferrous sulfate in the small intestine in humans and to obtain more information about the antioxidant defense mechanisms in the human small intestine in vivo.

\section{MATERIALS AND METHODS}

\section{Subjects}

Six healthy nonsmoking volunteers $(25 \pm 5 \mathrm{yr}, 3$ males, 3 females) without a history of a GI disorder participated in the present study. Volunteers were in good physical health at the time of participation as checked by medical interview. All subjects gave their written informed consent before participation. The study protocol was approved by the Ethics Committee of the University Hospital Maastricht, Maastricht, The Netherlands.

\section{Protocol}

After an overnight fast, a perfusion catheter was ingested orogastrically by each volunteer. The catheter consisted of three silicon tubes connected to a rubber balloon on the distal end of the catheter. One of the tubes called the sample port had three small openings at $5 \mathrm{~cm}$ proximal of the distal end of the catheter to enable fluid sampling from the small intestine at the level of the distal end of the catheter. The other two tubes were connected in an open loop with the balloon to enable fluid and air transport in and out of the balloon. A fourth lumen had a single opening at $45 \mathrm{~cm}$ from the distal end. This port, referred to as the perfusion port, served to administer a test solution directly into the duodenum.

After installation of the catheter tip into the stomach, the rubber balloon was filled with $1.5 \mathrm{ml}$ of mercury. Subjects were instructed to remain in the supine position on the right hand side with the upper body lifted $45^{\circ}$ and the feet raised $20 \mathrm{~cm}$ until the balloon entered the duodenum. Positioning of the catheter was checked with continuous $\mathrm{pH}$-registration at the tube tip. When the $\mathrm{pH}$ shifted from low $(\sim 1-2.5)$ to $\sim 4-6$, the mercury was aspirated and the balloon was subsequently inflated with $15 \mathrm{ml}$ of air. Subjects were instructed to stay in the supine position on the back with the upper body lifted $45^{\circ}$. The catheter propagated subsequently by the peristaltic movements of the GI tract. Catheter positioning was successful when the perfusion port was placed $\sim 5-10 \mathrm{~cm}$ distally from the pylorus. This was checked by a second $\mathrm{pH}$-registration channel, which was located at $5 \mathrm{~cm}$ proximal from the perfusion port. After positioning, the balloon was deflated to stop it from progressing in the GI tract. Throughout the experiment, the $\mathrm{pH}$ of the second $\mathrm{pH}$ channel was continuously registered to ensure proper positioning of the perfusion port. After the perfusion experiment, subjects removed the catheter by pulling it gently.

Via the perfusion port, a saline solution was injected at 10 $\mathrm{ml} /$ min during $195 \mathrm{~min}$. This period was necessary to reach steady-state conditions as was observed in pilot experiments (data not shown). Subsequently, a 300-ml saline solution containing $80 \mathrm{mg}$ elemental iron as ferrous sulfate (Merck,
Darmstadt, Germany) was perfused at $10 \mathrm{ml} / \mathrm{min}$ during 30 min. Finally, a saline solution was perfused again for $60 \mathrm{~min}$ to rinse out the iron solution and intestinal secretions.

Intestinal fluid samples were obtained by using the lever properties of the catheter. After an initial adaptation period of $195 \mathrm{~min}$, intestinal fluid content was levered through the sample lumen into a beaker placed in melting ice. Intestinal fluid excretions were pooled over 15-min intervals and stored at $-80^{\circ} \mathrm{C}$ until analysis.

\section{Biochemical Analysis of Intestinal Fluid Samples}

Thiobarbituric acid reactive substances assay. The determination of thiobarbituric acid reactive substances (TBARS) was based on the formation of a colored adduct of malondialdehyde (MDA) with 2-thiobarbituric acid (TBA). A $100 \mu \mathrm{l}$ sample was added to $900 \mu \mathrm{l}$ of a reagent [containing $0.12 \mathrm{M}$ TBA, $0.32 \mathrm{M} o$-phosphoric acid, $0.68 \mathrm{mM}$ butylated hydroxytoluene (BHT), and $0.01 \%$ (mass/vol) EDTA]. The mixture was incubated for $1 \mathrm{~h}$ at $100^{\circ} \mathrm{C}$ in a water bath. After cooling, the MDA-products were extracted with $500 \mu \mathrm{l}$ butanol. Then $30 \mu \mathrm{l}$ of the butanol layer were injected on an HPLC system (Agilent, Palo Alto, CA) equipped with a fluorescence detector, set on an excitation wavelength of $532 \mathrm{~nm}$ and an emission wavelength of $553 \mathrm{~nm}$, and a Nucleosil C18 column $(150 \times 3.2 \mathrm{~mm})$ particle size $5 \mu \mathrm{m}$ (Supelco, PA). Samples were eluted with $65 \%$ (vol/vol) $25 \mathrm{mM} \mathrm{PBS} \mathrm{(pH} \mathrm{4.8)} \mathrm{and} \mathrm{35 \%}$ (vol/vol) methanol. A calibration curve was constructed by using malonaldehyde bis(diethylacetal) as standard.

Antioxidant capacity assay. The antioxidant capacity assay was carried out as described previously (24a) with some modifications. The 2,2'-azinobis-(3-ethylbenzthiazoline-bsulfonate $\left(\mathrm{ABTS}^{+}\right.$) was produced by incubating a solution of $0.23 \mathrm{mM}$ ABTS and $2.3 \mathrm{mM}$ 2,2'-azobis-(2-amidinopropane) hydrochloric acid (ABAP) in $100 \mathrm{mM}$ sodium phosphate buffer $\mathrm{pH} 7.4$ at $70^{\circ} \mathrm{C}$ until the absorption of the solution at $734 \mathrm{~nm}$ was between 0.680 and 0.720 . Deproteination was done by mixing the sample with an equal volume of a solution of $10 \%$ (wt/vol) TCA. In the reaction of antioxidants with the blue/green $\mathrm{ABTS}^{\cdot+}$, the blue/green color disappears. This decolorization after $5 \mathrm{~min}$ is determined spectrophotometrically at $734 \mathrm{~nm}$. The reduction in absorbance is related to that of Trolox, a synthetic, hydrophilic vitamin $\mathrm{E}$ analog, which gives the Trolox equivalent antioxidant capacity (TEAC) value. The TEAC value is calculated as molar Trolox equivalents of the sample.

Glutathione assay. Total glutathione was determined by using the recycling method (25). To $50 \mu \mathrm{l}$ of a $100 \mu \mathrm{l}$ sample of a $0.4 \mathrm{mM}$ NADPH/0.3 mM 5,5'-dithiobis(2-nitrobenzoic acid) solution in $143 \mathrm{mM}$ PBS ( $\mathrm{pH} 7.4)$ containing $6.3 \mathrm{mM}$ EDTA, is added in a 96-well plate. The reaction is then started by adding $50 \mu \mathrm{l}$ of a solution containing $4 \mathrm{U} / \mathrm{ml}$ glutathione reductase. The increase of the absorption $(\Delta \mathrm{A} /$ min) is followed for $2 \mathrm{~min}$ at $405 \mathrm{~nm}$. The $\Delta \mathrm{A} / \mathrm{min}$ of the samples is compared with that of the calibrators and the concentration of total glutathione is calculated.

Uric acid assay. Uric acid was determined in ultra filtrates by using an HPLC method described previously (15) with minor modifications. The sample was filtered over a $3-\mathrm{kDa}$ filter unit (Centrex UF 0.5; Schleicher \& Schuell, Dassel, Germany) by centrifugation for $45 \mathrm{~min}$ at $14,000 \mathrm{~g}$ and $4^{\circ} \mathrm{C}$. Then $25 \mu \mathrm{l}$ of the filtrates was analyzed on the HPLC. The system (Agilent) consisted of a Hypersil BDS C-18 endcapped column $(125 \times 4 \mathrm{~mm})$, particle size $5 \mu \mathrm{m}$ (Agilent), with a mobile phase of $5 \mathrm{mM}$ sodium phosphate buffer $(\mathrm{pH}$ 3.3). Detection was performed by using a variable wavelength detector set on a wavelength of $292 \mathrm{~nm}$. Concentra- 
tions of uric acid were calculated by using a calibration curve of uric acid.

\section{Statistics}

Differences were assessed by univariate ANOVA using SPSS version 10.0 software. Differences were regarded as significant when $P<0.05$. Multiple comparisons, used to localize time differences, were adjusted with the least significant difference.

\section{RESULTS}

One to two hours after ingestion of the catheter, the distal end of the catheter entered the duodenum. Catheter positioning was completed within 5 to $8 \mathrm{~h}$ in all volunteers.

TBARS levels were significantly higher at 15, 30, 45, and $60 \mathrm{~min}$ after the start of the ferrous sulfate perfusion compared with the baseline level measured at $t=$ $0(P<0.05)$ and returned to baseline levels after 90 $\min$ (Fig. 1).

The TEAC of the intestinal fluid was significantly higher at 30 and 45 min after the start of the ferrous sulfate perfusion compared with the baseline level measured at $t=0(P<0.05)$ (Fig. 2).

Median alkaline phosphatase concentrations of the perfusate samples did not differ significantly between $t=0$ and $t=30 \mathrm{~min}(502 \pm 377$ and $510 \pm 363 \mathrm{U} / \mathrm{l}$, respectively).

Uric acid concentrations of the perfusate samples were not significantly different from baseline during the first 75 min after the start of the ferrous sulfate perfusion (Table 1 ). At $t=90$, uric acid was statistically lower than baseline values $(P<0.05)$.

Glutathione concentrations in the perfusate samples were under the detection limit of the equipment $(<0.10 \mu \mathrm{M})$.

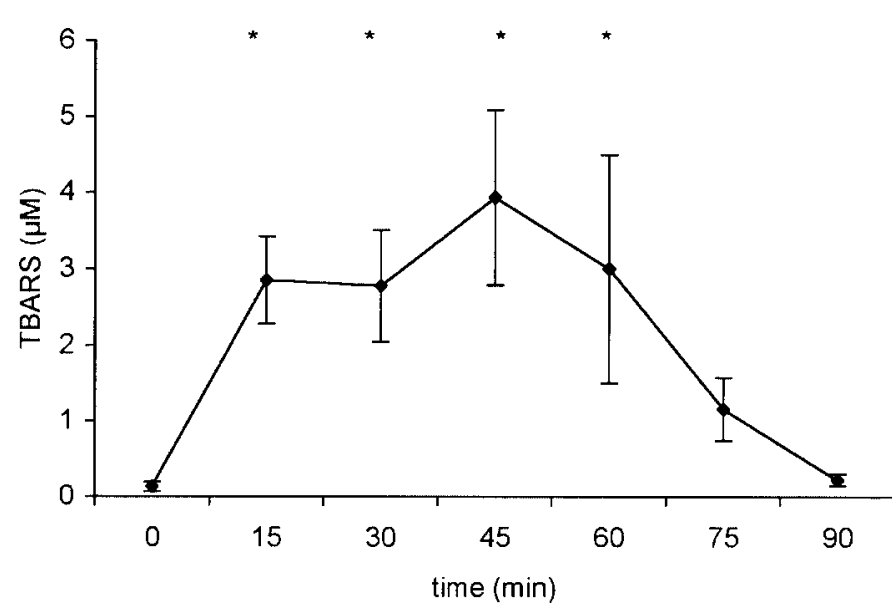

Fig. 1. Thiobarbituric acid reactive substances (TBARS) concentrations in intestinal perfusion samples, collected over 15-min intervals after perfusion of a $40-\mathrm{cm}$ segment in the proximal small intestine in 6 subjects. Baseline values at $t=0$ were obtained during saline perfusion. Subsequently, saline containing $80 \mathrm{mg}$ elemental iron as ferrous sulfate was perfused for $30 \mathrm{~min}$. Finally, saline was perfused for $60 \mathrm{~min}$ at $10 \mathrm{ml} / \mathrm{min}$ (means $\pm \mathrm{SE}$; differences vs. $t=0$ tested with ANOVA; $* P<0.05)$.

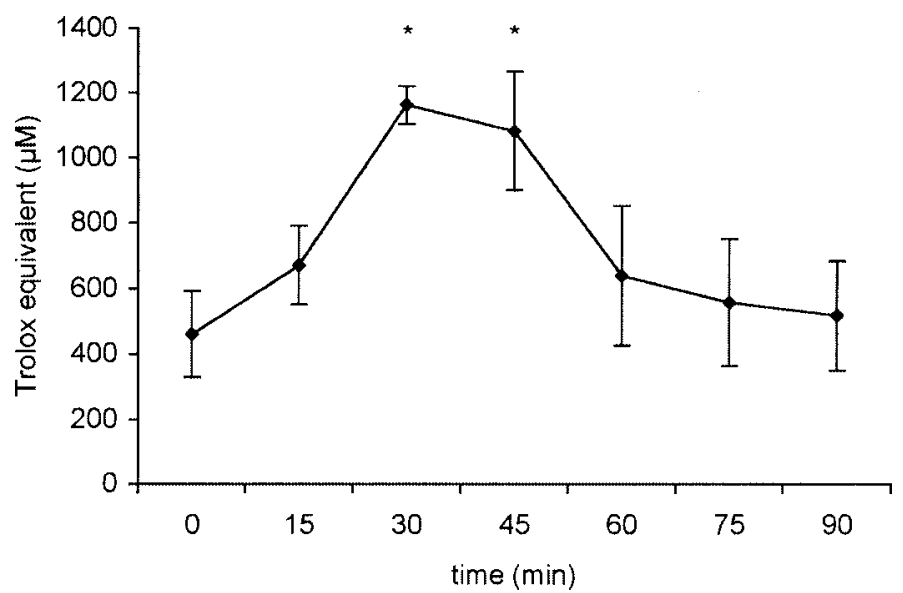

Fig. 2. Antioxidant capacity in intestinal perfusion samples, collected over 15-min intervals after perfusion of a $40-\mathrm{cm}$ segment in the proximal small intestine in 6 subjects. Baseline values at $t=0$ were obtained during saline perfusion. Subsequently saline containing $80 \mathrm{mg}$ elemental iron as ferrous sulfate was perfused for $30 \mathrm{~min}$. Finally saline was perfused for $60 \mathrm{~min}$ at $10 \mathrm{ml} / \mathrm{min}$ (means $\pm \mathrm{SE}$; differences vs. $t=0$ tested with ANOVA; $* P<0.05$ )

\section{DISCUSSION}

The present study clearly shows that iron ingestion in vivo induces intestinal oxidative damage as indicated by the occurrence of lipid peroxidation. The magnitude of the TBARS concentration in the intestinal fluid samples as a result of iron ingestion was remarkably high. The TBARS assay was applied to estimate MDA concentration, which is an end product of lipid peroxidation. MDA is a well-accepted parameter of oxidative damage (10). However, it is not specifically produced as a result of free radicals attack, but may be formed during the ex vivo sample incubation stage. To prevent formation of MDA ex vivo, the chain-breaking antioxidant BHT was added. The ability of BHT to prevent TBARS formation during the analytical assay was checked in ex vivo experiments with intestinal fluid samples. In these experiments, we observed an instantaneous rise in TBARS formation on iron addition, but BHT was effective in preventing TBARS formation during the assay. Other possible analytical shortcomings of the conventional TBARS-assay are resolved by the use of the applied HPLC technique (11). Therefore, in the present study TBARS provides an accurate indicator of oxidative damage in vivo. The

Table 1. Uric acid concentrations in intestinal perfusion samples pooled over 15-min periods

\begin{tabular}{cl}
\hline \hline Time, $\min$ & Uric acid, $\mu \mathrm{M}$ \\
\hline 0 & $37.9 \pm 15.6$ \\
15 & $34.4 \pm 15.7$ \\
30 & $32.5 \pm 12.6$ \\
45 & $27.1 \pm 8.2$ \\
60 & $25.2 \pm 4.8$ \\
75 & $28.7 \pm 8.7$ \\
90 & $26.9 \pm 10.2$ \\
\hline
\end{tabular}

Values are means $\pm \mathrm{SD} ; n=6$. 
finding that antioxidant capacity increases in the lumen of the small intestine after an oxidative challenge has not been described previously. The rapid and massive increase in antioxidant capacity of the intestinal fluid samples indicates a powerful defense mechanism of the small intestine against exogenous oxidants.

TBARS concentrations in the intestinal fluid samples after the iron challenge are roughly 3-5 times higher than those observed in plasma in healthy adults. This is a highly interesting finding in the view of the dilution of the intestinal fluid samples. In pilot experiments, we measured the dilution of the intestinal fluid with the saline or saline/iron solution in the intestinal segment by the addition of an inert marker, lactulose, to the ingoing solution and subsequent measurement of the lactulose concentration in the perfusate samples. A dilution of $\sim 100$-fold was found in all samples. This dilution was constant throughout the experiment (data not shown). In view of the fact that sample dilution did not change during the experiment, independently of the presence or absence of iron, intestinal fluid dilution did not interfere with the results of the study and hence, was not measured in the present study.

On average, $\sim 15 \mathrm{mg}$ of iron is present in the daily diet. Approximately $2.5 \mathrm{mg}$ iron entering the intestine will be absorbed. Approximately $1 \%$ of the dietary iron remains in the lumen in a form likely to participate in free radical generation. During oral iron therapy in adults using dosages of $60-195 \mathrm{mg}$ iron/day, this proportion remains the same, resulting in a much larger amount of iron available for Fenton reactions. During Fenton chemistry, ferrous iron catalyzes the formation of hydroxyl radicals in the presence of superoxide anion radicals and hydrogen peroxide, both produced as a result of normal metabolism. Hydroxyl radicals are highly reactive and can inflict damage to any biologic molecule in its direct environment. The free electron can transfer to another molecule and hence, initiate a cascade of damaging reactions. Previously, it was shown that the free radical generating capacity from feces in healthy volunteers was markedly increased after iron supplementation ( $19 \mathrm{mg} /$ day iron as ferrous sulfate for 14 day) (14). However, this was measured in fecal samples ex vivo in an in vitro assay. This does not necessarily reflect the conditions from the present study in which the true effects of iron ingestion in the small intestine in vivo were investigated. The results of the present study confirm the finding that iron ingestion leads to an increase in free radical production in the gut. The model used in the present study mimics ingestion of an oral iron supplement, which dissolves in the gastric juice and is subsequently released gradually into the small intestine.

From the data (Fig. 1) it is clear that oxidative damage occurs immediately after iron administration into the small intestine. This damage continues during saline perfusion after the ferrous sulfate perfusion. This is likely due to the low perfusion flow in the experimental setup. After discontinuation of the iron perfusion, it takes some time to rinse out all of the iron and the intestinal juices secreted during the iron perfusion from the small intestine. After $60 \mathrm{~min}$ of saline perfusion, no iron-induced rise in TBARS is observed in the intestinal fluid samples anymore. These data are in line with those of a rat study in which it was shown that high dosages of iron supplements induce lipid peroxidation in the colon (21). Any effects of iron supplements in the small intestine were not investigated in that study.

The lipid peroxidation observed in the present study preceded a marked rise in TEAC (Fig. 2). From this, it may be concluded that iron-induced oxidative stress induces the release of an antioxidative component in the small intestine. As for the TBARS concentrations, the TEAC values are also remarkably high, especially in view of the previously mentioned dilution of the intestinal fluid samples with the ingoing solution. The data of the present study indicate that a powerful physiological mechanism in the small intestine protects against iron-induced oxidative damage. In view of the fast release of the antioxidant(s), it is unlikely that the iron-induced oxidative damage directly induced production of an antioxidative agent, which is subsequently released into the lumen. It is more likely that an antioxidant already present in a storage compartment in the small intestine was released on oxidative damage. In the present study, all samples were completely deproteinized during the TEAC assay. Sample deproteination is routine practice during the TEAC assay to reduce the analysis of variance. In pilot experiments, we observed that sample deproteination did not affect the average TEAC values compared with duplicate nondeproteinized samples. Hence, the high antioxidant capacity was exclusively caused by a nonprotein species. This excludes a role for enzymatic antioxidants or metallothionines in the observed rise in antioxidant capacity.

The rise in TEAC might be explained by lysis of epithelial or mucosal cells. If the membranes of intact cells were disrupted, its cellular content was excreted into the lumen. As a result, the antioxidant capacity would predominantly originate from the cytosolic antioxidant capacity of the epithelial cells. However, this would have been accompanied by a rise in total alkaline phosphatase, which we did not observe. Also, removal of intact epithelial cells present in the intestinal fluid samples by centrifugation did not significantly affect the antioxidant capacity of the samples (data not shown). This suggests that the strong rise in TEAC after iron-induced oxidative stress was not due to cell lysis but was brought about by a specific antioxidant mechanism.

Data regarding the nonprotein antioxidant capacity of the small intestine are scarce. It was shown in a rat study (17) that the small intestine has a powerful reducing capacity, which is protective against triglyceride hydroperoxides. The underlying mechanism or the site of action (luminal, mucosal, or epithelial) was not identified. In the present study, glutathione and uric acid were determined in the intestinal fluid samples in an attempt to identify the origin of the rise in 
antioxidant capacity after iron perfusion. Due to the intestinal fluid dilution by the perfusing solution, glutathione concentrations were below the detection threshold of the equipment used. Uric acid, a powerful antioxidant present in lung- and intestine epithelial lining fluid (12), was present in low amounts not affected by the iron intervention. Vitamin C, present in low amounts in most samples, did not show a correlation with antioxidant capacity (data not shown). Hence, neither of these antioxidants was responsible for the rise in antioxidant capacity after the iron challenge in the present study.

The perfusion model to investigate oxidative stress and antioxidant capacity in the human small intestine enabled us to determine the effects of a prooxidative agent over a standardized segment of the small intestine. A major advantage of the technique is the rather noninvasive protocol of the catheter positioning, because this occurred using normal peristaltic movements. The technique is applicable to healthy volunteers as well as patients. The perfusion technique can only be used to study a limited segment of the proximal small intestine. Hence, results may not be directly extrapolated to the entire small intestine. However, due to a decreasing nutrient concentration along the small intestine, nutrient-associated oxidative damage probably takes place predominantly in the proximal small intestine. The rate of perfusion needs to be as low as possible to avoid effects of the perfusion experiment on normal functioning of the small intestine. Because of the low perfusion flow, it is not possible to monitor acute, short-term responses in the small intestine. Additionally, sampling occurs at 15-min intervals to ensure sufficient sample collection during each collection interval. The perfusion technique provides the unique feature to study oxidative damage and antioxidant capacity in secretions of the small intestine in vivo in humans under strictly standardized conditions. This model is applicable to a variety of intestinal disorders associated with a disturbance in the equilibrium between oxidative stress and the antioxidant defense network. Increased oxidative stress occurs in acute and chronic inflammation, certain drugs, and nutrients. Decreased antioxidant capacity may be present in disorders of mucosal integrity and chronic malabsorption disorders associated with antioxidant deficiencies (8). A disturbance in the equilibrium between oxidative stress and the antioxidant defense network in the small intestine may be an important factor in the pathophysiology of these disorders. Additionally, the perfusion technique can be used to evaluate the efficiency of nutritional antioxidant interventions in restoring a sufficient antioxidant network against oxidative attack in the small intestine.

Iron ingestion induced Fenton-driven oxidative stress in the human small intestine, followed by a massive rise in total antioxidant capacity in the lumen. This rise may reflect the release of a powerful, yet unidentified, nonprotein antioxidant. Future work should focus on identification of this antioxidant and on the possibilities to increase the antioxidant capacity against oxidative stress with nutritional interventions in disorders related to a high intestinal oxidative stress or a low intestinal antioxidant defense network.

\section{REFERENCES}

1. Aghdassi E, Carrier J, Cullen J, Tischler M, and Allard JP. Effect of iron supplementation on oxidative stress and intestinal inflammation in rats with acute colitis. Dig Dis Sci 46: 10881094, 2001

2. Al-Momen AK, al-Meshari A, al-Nuaim L, Saddique A, Abotalib Z, Khashogji T, and Abbas M. Intravenous iron sucrose complex in the treatment of iron deficiency anemia during pregnancy. Eur J Obstet Gynecol Reprod Biol 69: 121-124, 1996.

4. Blakeborough MH, Owen RW, and Bilton RF. Free radical generating mechanisms in the colon: their role in the induction and promotion of colorectal cancer? Free Radic Res Commun 6: 359-367, 1989.

5. DeMaeyer E and Adiels-Tegman M. The prevalence of anaemia in the world. World Health Stat Q 38: 302-316, 1985.

6. Fodor I and Marx JJ. Lipid peroxidation of rabbit small intestinal microvillus membrane vesicles by iron complexes. Biochim Biophys Acta 961: 96-102, 1988.

7. Frewin R, Henson A, and Provan D. ABC of clinical haematology. Iron deficiency anaemia. BMJ 314: 360-363, 1997.

8. Geerling BJ, Badart-Smook A, Stockbrugger RW, and Brummer RJ. Comprehensive nutritional status in patients with long-standing Crohn disease currently in remission. Am J Clin Nutr 67: 919-926, 1998.

9. Gonzalez PK, Doctrow SR, Malfroy B, and Fink MP. Role of oxidant stress and iron delocalization in acidosis-induced intestinal epithelial hyperpermeability. Shock 8: 108-114, 1997.

10. Hageman JJ, Bast A, and Vermeulen NP. Monitoring of oxidative free radical damage in vivo: analytical aspects. Chem Biol Interact 82: 243-293, 1992.

11. Halliwell $B$ and Chirico Lipid peroxidation: its mechanism S, measurement, and significance. Am J Clin Nutr 57: 715S-724S; discussion 724S-725S, 1993.

12. Karasawa Y, Ishi IT, and Kubota T. Absorption and metabolism of purines by the small intestine of the chicken. Comp Biochem Physiol A 99: 235-240, 1991.

13. Lih-Brody L, Powell SR, Collier KP, Reddy GM, Cerchia R, Kahn E, Weissman GS, Katz S, Floyd RA, McKinley MJ, Fisher SE, and Mullin GE. Increased oxidative stress and decreased antioxidant defenses in mucosa of inflammatory bowel disease. Dig Dis Sci 41: 2078-2086, 1996.

14. Lund EK, Wharf SG, Fairweather-Tait SJ, and Johnson IT. Oral ferrous sulfate supplements increase the free radicalgenerating capacity of feces from healthy volunteers. Am J Clin Nutr 69: 250-255, 1999.

15. Lux O, Naidoo D, and Salonikas C. Improved HPLC method for the simultaneous measurement of allantoin and uric acid in plasma. Ann Clin Biochem 29: 674-675, 1992.

16. Marx JJ and van Asbeck BS. Use of iron chelators in preventing hydroxyl radical damage: adult respiratory distress syndrome as an experimental model for the pathophysiology and treatment of oxygen-radical-mediated tissue damage. Acta Haematol 95: 49-62, 1996.

17. Mohr D, Umeda Y, Redgrave TG, and Stocker R. Antioxidant defenses in rat intestine and mesenteric lymph. Redox Rep 4: 79-87, 1999 .

18. Nelson RL, Yoo SJ, Tanure JC, Andrianopoulos G, and Misumi A. The effect of iron on experimental colorectal carcinogenesis. Anticancer Res 9: 1477-1482, 1989.

19. Odetti P, Valentini S, Aragno I, Garibaldi S, Pronzato MA, Rolandi E, and Barreca T. Oxidative stress in subjects affected by celiac disease. Free Radic Res 29: 17-24, 1998.

20. Reifen R, Matas Z, Zeidel L, Berkovitch Z, and Bujanover Y. Iron supplementation may aggravate inflammatory status of colitis in a rat model. Dig Dis Sci 45: 394-397, 2000.

21. Rimbach G, Markant A, Most E, and Pallauf J. Liver and colon oxidant status in growing rats fed increasing levels of dietary iron. J Trace Elem Med Biol 11: 99-104, 1997. 
22. Siegers CP, Bumann D, Trepkau HD, Schadwinkel B, and Baretton G. Influence of dietary iron overload on cell proliferation and intestinal tumorigenesis in mice. Cancer Lett 65: 245-249, 1992.

23. Srigiridhar K and Nair KM. Iron-deficient intestine is more susceptible to peroxidative damage during iron supplementation in rats. Free Radic Biol Med 25: 660-665, 1998.

24. Srigiridhar K, Nair KM, Subramanian R, and Singotamu L. Oral repletion of iron induces free radical mediated alterations in the gastrointestinal tract of rat. Mol Cell Biochem 219: 91-98, 2001.

24a.Van den Berg R, Haenen G, van den Berg H, and Bast A. Applicability of an improved Trolox equivalent antioxidant ca- pacity (TEAC) assay for evaluation of antioxidant capacity measurements of mixtures. Food Chemistry: 511-517, 1999.

25. Vandeputte C, Guizon I, Genestie-Denis I, Vannier B, and Lorenzon G. A microtiter plate assay for total glutathione and glutathione disulfide contents in cultured/isolated cells: performance study of a new miniaturized protocol. Cell Biol Toxicol 10: 415-421, 1994.

26. Wurzelmann JI, Silver A, Schreinemachers DM, Sandler RS, and Everson RB. Iron intake and the risk of colorectal cancer. Cancer Epidemiol Biomarkers Prev 5: 503-507, 1996.

27. Yamada T and Grisham MB. Role of neutrophil-derived oxidants in the pathogenesis of intestinal inflammation. Klin Wochenschr 69: 988-994, 1991.

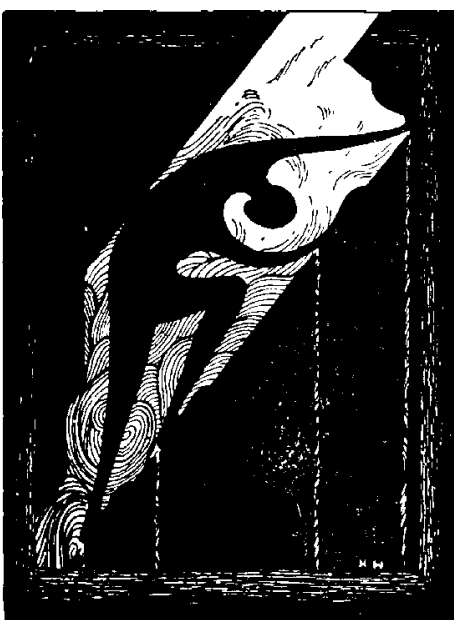

